\title{
Comparing the vascular thromboembolic events following arteriovenous fistula in Chinese population with end-stage renal diseases receiving Clopidogrel versus Beraprost sodium therapy: a retrospective cohort study
}

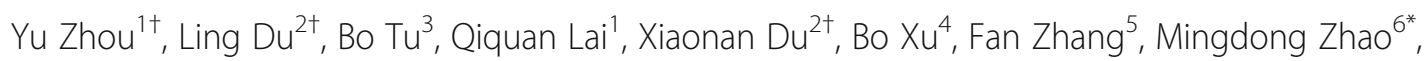
Ziming Wan $^{1 *}$ and Jiajie Lai ${ }^{7 *}$

\begin{abstract}
Background: To assess the time to first on-study vascular thromboembolic events (VTEs) of clopidogrel (CL) or beraprost sodium (BPS) in Chinese population with end-stage renal disease (ESRD) treated with arteriovenous fistula (AVF) surgery.

Methods: From Jan 2009 to May 2015, 346 ESRD cases suffering an AVF surgery and undergoing oral administration of $75 \mathrm{mg} \mathrm{CL}$ (initial dose of $300 \mathrm{mg}$ ), 1 time/day, for 4 weeks or 40 Mg BPS, 3 times/day, for 4 weeks were retrospectively assessed. The primary outcome was time to first on-study VTE.

Results: In total, 222 ESRD cases (CL, $n=112 ; \mathrm{BPS}, n=110$ ) were assessed, with a median follow-up time of 38.1 months (range, 37-40 months). The mean time to first on-study VTE was 1.2 weeks (0.5-2.3) and 1.8 weeks (1.2-3.8) for CL and $\mathrm{BPS}$, respectively ( $\mathrm{HR} 0.27,95 \% \mathrm{Cl} 0.16-1.45 ; P=0.00)$. An increased incidence of VTEs was found during the 1 th-month follow-up, with rates of 14.2 and $5.5 \%$ for $C L$ and BPS, respectively $(P=0.03)$. The difference persisted over time, with rates of 24.1 and $11.8 \%$ at final follow-up, respectively $(P=0.02)$.

Conclusion: $\mathrm{CL}$ with an increased risk of VTEs tended to have a VTE within the 1st month after cessation compared with BPS.
\end{abstract}

Keywords: Clopidogrel, Beraprost sodium, Vascular thromboembolic event, Arteriovenous fistula, Chinese population

\footnotetext{
*Correspondence: zhaonissann@163.com; wzmbruce001@163.com; 342756019@qq.com

${ }^{\dagger}$ Yu Zhou, Ling Du and Xiaonan Du contributed equally to this work. ${ }^{6}$ Department of Orthopaedics, Jinshan Hospital, Fudan University, Longhang Road No. 1508, Jinshan District, Shanghai 201508, China

'Department of Nephrology, The First Affiliated Hospital of Chongqing Medical University, Youyi Road No.1, Yuzhong District, Chongqing 400016, China

${ }^{7}$ Department of Gynaecology and obstetrics, The First Affiliated Hospital of Sun Yat-sen University, Huangpu East Road No. 183, Huangpu District, Guangzhou 510700, China

Full list of author information is available at the end of the article
}

(c) The Author(s). 2018 Open Access This article is distributed under the terms of the Creative Commons Attribution 4.0 International License (http://creativecommons.org/licenses/by/4.0/), which permits unrestricted use, distribution, and reproduction in any medium, provided you give appropriate credit to the original author(s) and the source, provide a link to the Creative Commons license, and indicate if changes were made. The Creative Commons Public Domain Dedication waiver (http://creativecommons.org/publicdomain/zero/1.0/) applies to the data made available in this article, unless otherwise stated. 


\section{Background}

Establishing and maintaining long-term vascular access is a prerequisite for hemodialysis in patients with end-stage renal disease (ESRD) [1-4]. An ideal vascular access should provide sufficient blood flow for hemodialysis to ensure the completion of hemodialysis procedures, as well as long enough use time and as few complications as possible, which is an important condition for sustaining long-term survival [5]. During the treatment of arteriovenous fistula (AVF), it is possible that anastomotic embolism can often lead to failure of fistula $[6,7]$. Therefore, long-term dialysis patients have to face treatment trouble and mental pain $[8,9]$. ESRD patients are considered at increased risk for vascular thromboembolic events (VTEs) after an AVF surgery [6]. The use of antiplatelet medications, specifically clopidogrel (CL) and beraprost sodium (BPS), is steadily increasing $[10,11]$. Previous studies show that patients receiving either of these medications are at decreased risk for VTEs after an AVF surgery, but the risk in a large, generalizable Chinese population is unknown $[12,13]$. To our knowledge, a direct comparison between $\mathrm{CL}$ and BPS has rarely been reported in the previous literature. Despite poor efficacy in ESRD patients, BPS and CL remain promising options to decrease AVF-related VTEs. Nevertheless, several unanswered questions remain.

The aim of this study was to assess the outcome of CL or BPS using time to first on-study VTEs as the primary endpoint in ESRD cases suffering an AVF surgery in Chinese population to further improve the design of the therapeutic regime.

\section{Methods}

\section{Study population}

All ESRD cases who were diagnosed according to standard criteria [14] and underwent an AVF surgery, following by peroral administration of $40 \mu \mathrm{g}$ BPS(Beijing Ted Pharmaceutical Co., LTD., China, drug specifications: $20 \mu \mathrm{g}$ ), 3 times per day, for 1 month or $75 \mathrm{mg} \mathrm{CL}$ (initial dose of $300 \mathrm{mg}$, Hangzhou Sanofi Pharmaceutical Co., LTD., China, drug specifications: $75 \mathrm{mg}$ ), 1 time per day, for 1 month were identified from three medical centers (Jinshan Hospital, Fudan University; the First Affiliated Hospital, Sun Yat-sen University; the First Affiliated Hospital of Chongqing Medical University) between Jan 2009 and May 2015. Inclusion criteria: age ranging 20-50 years; within 4 weeks prior to surgery, no cardiovascular-related medications were applied in any case; dialysis was performed for 3 times/week, 3 4 h/time. Main exclusion criteria: chronic wasting disease; myelodysplastic syndrome; cardiovascular dynamic instability; coagulopathy; hemorrhagic endovasculitis; a long-term history of receiving the BPS or CL treatment; deterioration of renal function during follow-up; co-occurring tumour; ChildTurcotte-Pugh classification of $\mathrm{C}$ for liver function; clinical data which might lead to informative censoring for time to first on-study VTEs; loss of follow-up; interruption or modification of BPS or CL regimen; dropout owing to or severe infection; life expectancy less than 2 years; concomitant mental illness; an American Society of Anesthesiologists (ASA) score of IV or V. Patients would be censored at any time when they were loss to follow-up for the follow-up period, for whatever reason. Data collection for these cases was censored at completion of the study.

\section{Surgical technique}

Preoperatively, the arteries with strong fluctuation and thick veins were marked. After local anesthesia, the longitudinal incision of the skin was performed in the view of the microscope for $1.5-2 \mathrm{~cm}$, following by exposure, dissociation of cephalic vein and artery. The distal end of the cephalic vein was ligated. After the expansion of the proximal cephalic vein, the intravenous injection of heparin saline is used to test whether the cephalic vein is obstructed or not. The $45^{\circ}$ Angle pruning of the anastomosis was performed. The peripheral membrane of the vascellum was clipped and the vascellum was repeatedly washed with heparin saline. The radial artery between the vascular clamps was distended by injection of heparin saline with a fine needle. The radial artery was opened longitudinally with a sharp knife, about 4-5 $\mathrm{mm}$ in length. End-to-side continuous anastomosis of the cephalic vein and radial artery was performed in line with relatively mature surgical techniques $[15,16]$. Anastomoses were formed using 8.0 prolene. It should be noted that blood vessels should not be warped or subjected to pressure. During the suture process, the needle spacing should be as consistent as possible. After the completion of the anastomosis, the arterial clip was released and then clamped, followed by the intravenous clip. After $5 \mathrm{~min}$, all the vascular clips were released. A small amount of blooding at the vascular anastomosis point can be gently pressed to stop the bleeding.

\section{Definitions of main descriptive variables}

The primary endpoint was time to first on-study VTEs. Prior to the start of the study, an Endpoint Judgment Committee (EJC) that comprised of 3 independent ultrasound doctors who are not involved directly in the study was established in each institution. VTEs were defined as an interruption of blood flow owing to anastomosis-related stenosis or thrombus, which was determined by an EJC based on colour Doppler ultrasonography. Primary patency at the anastomoses was defined as the interval from the time of access to any intervention which involved in restoring or sustaining patency. Patency was censored by three independent ultrasound doctors at the date of on-study VTE survey. 
A venous diameter greater than $5 \mathrm{~mm}$ can be adapted to the need for dialysis and is not easily clogged. The success rate of internal fistula $=$ patency number/total number ${ }^{*} 100 \%$. The analysis of the rate for time to first and subsequent on-study VTEs is based on an Andersen-Gill model [17]. Major bleeding events were defined as prior statements [18].

\section{Statistical analysis}

The data up to the primary analysis cut-off were valid data. Categorical variables were expressed as frequencies and percentages. Quantitative variables are presented as either the mean $+/$ - standard deviation (SD) or median [interquartile range (IQR)] depending on the data distribution. Bivariate analyses involving ANOVA and Chi-square tests were applied as appropriate to assess between-group differences. The Kaplan-Meyer analysis were constructed to exhibit the incidence of the primary study endpoint. In computations of event rates, follow-up time was censored at lost to follow up or all-cause death. All- cause death was ascertained until the end date of the data cut-off. The Cox regression models was used to assess hazard ratio (HR). A $P<0.05$ was considered significantly different. Statistical analysis is processed by IBM-SPSS (version 24.0, Inc., NY, USA).

\section{Results}

\section{Baseline characteristics}

During the study period, 346 consecutive ESRD cases who underwent an AVF surgery and received peroral administration of CL or BPS were identified. Of 346, 222 cases $(C L, n=112$; BPS, $n=110)$ met criteria. Details are summarized in Fig. 1. Follow-up regarding the primary endpoint was completed in August 2016. Median follow-up time is 38.1 months (range, 37-40). Patient-related baseline data are showed in Table 1. No between-group significant differences were detected in medical related diseases following the initiation of drug intervention. Patient-related baseline characteristics were well balanced.

\section{VTE incidence}

The rates of the VTEs for the CL and BPS groups were $24.1 \%(27 / 112)$ and $11.8 \%(13 / 110)$, respectively (Table 2$)$. The mean time to first on-study VTE was 1.2 weeks $(0.5-2.3)$ and 1.8 weeks $(1.2-3.8)$ for $\mathrm{CL}$ and BPS, respectively (HR $0.27,95 \%$ CI $0.16-1.45 ; P=0.00$ ).

$\mathrm{CL}$ tended to have a higher incidence of VTEs in comparison with BPS at final follow-up (27 vs. 13, respectively). During the 1st month after cessation, 16 (16/112) cases were diagnosed with a VTE; During the 2nd month, 3 underwent a VTE (3/112); Between 3rd month and data cut-off, 8 suffered a VTE $(8 / 112)$. There is a distributed phenomenon of VTEs within the 1st month in the CL-treated cohort. However, it failed to be observed or was not apparent in the BPS-treated cohort. During the 1st month after cessation, 6 patients $(3 / 110)$ had a VTE; during the 2nd month, 2 (2/110) underwent a VTE; from 3rd month to data cut-off, 5 (5/110) underwent a VTE. A decrease risk of VTEs by $47 \%$ was detected in BPS compared with CL ( HR, 2.04; 95\% CI $0.12-2.17 ; P=0.001$ ), as presented in Table 3 and Fig. 2 .

\section{Adverse events}

A major bleeding event happened among 5.4\% of CL-treated cohort; and such event occurred in $4.5 \%$ of BPS-treated cohorts $(P=0.78)$. Compared with BPS, CL was not associated with an increased risk in major bleeding (HR1.06; 95\%CI: 0.62-1.74). No significant differences were detected in other adverse events.

\section{Discussion}

In the current study evaluating time to first on-study VTE among at-risk ESRD patients undergoing an AVF surgery, to our knowledge the largest AVF study to date, the major finding was that BPS demonstrated superiority to CL by decreasing the occurrence of VTEs (primary endpoint) in ESRD patients who underwent an AVF surgery. Notably, CL tended to result in a first on-study VTE within the 1st month after the cessation of drug administration compared with BPS.

At the study start, we hypothesized that excellent primary endpoint would be attributed to CL on account of several previous findings. Unfortunately, in our study, $\mathrm{CL}$ was inclined to lead to an increased risk of first on-study VTEs, which seemed to contradict its predictive efficacy of VTEs. The reasons for the finding remain indistinct and can be elaborated different versions in some recent studies in ESRD patients who underwent an AVF surgery $[10,11]$. An explanation for the opposite finding is unhesitatingly unavailable, although CL which is commonly used to prevent ATEs might contribute to the difference [19]. The occurrence of VTEs remains a life-threatening clinical challenge, although considerable benefits of CL have been showed in previous clinical trials [20-22]. Thus far, several literatures have shown the negative impact of CL variability on VTEs in ESRD patients who underwent an AVF surgery, regardless of the prevention of heart attack and strokes in cardiovascular cases [23, 24]. Undeniably, our study underscored the potential CL-related risks that CL adopted in ESRD patients, which, compared with BPS, tended to be associated with a poor prognosis.

There is a body of evidence suggesting that poor vascular elasticity and endovascular stenosis underlie a significant proportion of patients of VTEs [25, 26]. Endometrial damage following an AVF surgery can contribute to the occurrence of VTEs $[25,27]$. In terms of 
From Jan 2009 to May 2015, 346 ESRD cases suffering an AVF surgery and undergoing oral administration of $75 \mathrm{mg}$ CL (initial dose of $300 \mathrm{mg}$ ), 1 time/ day, for 4 weeks or $40 \mu \mathrm{g}$ BPS, 3 times/day, for 4 weeks

\begin{tabular}{|c|c|c|}
\hline $\begin{array}{l}\text {-Child-Turcotte-Pugh classification of } C \text { for liver } \\
\text { function }(n=7) \\
\text {-clinical data which might lead to informative } \\
\text { censoring for time to first on-study VTEs }(n= \\
\text { 13) } \\
\text {-loss of follow-up }(n=17) \\
\text {-interruption or modification of BPS or CL } \\
\text { regimen( } n=11) \\
\text {-dropout owing to or severe infection }(n=16) \\
\text {-life expectancy }<2 \text { year }(n=9) \\
\text {-concomitant mental illness }(n=4) \\
\text {-ASA score of IV or } V(n=3)\end{array}$ & \multicolumn{2}{|c|}{$\begin{array}{l}\text { Reasons for exclusion }(n=124) \\
\text {-chronic wasting disease }(n=3) \\
\text { - } \text {-myelodysplastic syndrome }(n=4) \\
\text {-cardiovascular dynamic instability }(n=3) \\
\text {-coagulopathy }(n=2) \\
\text {-hemorrhagic endovasculitis }(n=5) \\
\text {-a long-term history of receiving the BPS or CL } \\
\text { treatment }(n=11) \\
\text {-deterioration of renal function during follow- } \\
\text { up }(n=4) \\
\text {-co-occurring tumour }(n=12)\end{array}$} \\
\hline \multicolumn{3}{|c|}{ Eligible for final analysis $(n=222)$} \\
\hline Group $C L(n=112)$ & Allocation & Group BPS $(n=110)$ \\
\hline \begin{tabular}{|l} 
Lost to follow-up \\
1months postoperatively \\
-Died of infectious disease $(n=1)$ \\
-Died of cardiovascular disease $(n=2)$ \\
-Died of hypertensive complications $(n=$ \\
$2)$ \\
2 months postoperatively \\
-Died of cardiovascular disease $(n=1)$ \\
-Died of infectious diseases $(n=3)$ \\
-Died of septicemia and malignant \\
lymphoma $(n=1)$ \\
3 months postoperatively \\
-Died of septicemia and malignant \\
lymphoma( $n=2)$ \\
-Died of death stroke( $n=1)$ \\
-Died of infectious diseases $(n=2)$ \\
-Died of diabetic diseases $(n=1)$ \\
-Died of cardiovascular disease $(n=2)$ \\
subsequent follow-up \\
-Died of hypertensive complications, \\
cancer, diabetic complications, car \\
accidents, infectious diseases, drowning, \\
and suicide $(n=12)$
\end{tabular} & Follow-up & $\begin{array}{l}\text { Lost to follow-up } \\
1 \text { months postoperatively } \\
\text {-Died of death stroke }(n=1) \\
\text {-Died of cardiovascular disease }(n=3) \\
\text {-Died of hypertensive complications }(n= \\
1) \\
\text {-Died of infectious diseases }(n=2) \\
2 \text { months postoperatively } \\
\text {-Died of cardiovascular disease }(n=2) \\
\text {-Died of pulmonary inflammation }(n=1) \\
\text {-Died of infectious disease }(n=1) \\
3 \text { months postoperatively } \\
\text {-Died of infectious disease }(n=1) \\
\text {-Died of diabetic complications }(n=2) \\
\text {-Died of cardiovascular disease }(n=1) \\
\text {-Died of hypertensive complications }(n= \\
2) \\
\text { subsequent follow-up } \\
\text {-Died of high blood pressure } \\
\text { complications, diabetic complications, } \\
\text { car accidents, cancer, sepsis, pulmonary } \\
\text { inflammation, commit suicide }(n=19)\end{array}$ \\
\hline Group CL $(\mathrm{n}=82)$ & & Group BPS $(n=74)$ \\
\hline
\end{tabular}

Fig. 1 Flow diagram demonstrating methods for the population-based identification to assess the time to first on-study vascular thromboembolic events (VTEs) of clopidogrel (CL) or beraprost sodium (BPS) in Chinese population with end-stage renal disease (ESRD) treated with arteriovenous fistula (AVF)

the success rate, there are many substantial studies indicated that BPS has contributed to the improvement of the success rate of AVFs in the ESRD patients compared with $\mathrm{CL}$, although a finding at odds with trends was detected in several previous literatures [10, 28]. Nevertheless, the superiority of BPS has gained increasing recognition, and low VTEs in BPS is most likely explained by BPS itself [29]. Although the success rate of VTEs in our study was lower than anticipated, our finding was comparable to the outcome of a previous meta analysis [27]. Furthermore, consistent with previous studies [30, 31], high VTEs which were detected in CL-treated cohort were associated with an increased risk of thrombus complication.

Our finding is inconsistent with several reports on the rate of VTEs [4, 5, 32,33]. A previous study by Yuo was a retrospective assessment only with a rather small number of cases, and the study failed to have a control group 
Table 1 Between-group comparison of baseline data

\begin{tabular}{|c|c|c|c|}
\hline Variable & $\mathrm{CL}(n=112)$ & $\operatorname{BPS}(n=110)$ & $P$ - value \\
\hline Age (y) & & & $0.73^{* a}$ \\
\hline $20-39$ & 35 & 33 & \\
\hline $40-59$ & 44 & 42 & \\
\hline $60-79$ & 33 & 35 & \\
\hline Sex, No. M/F & $60 / 52$ & $59 / 51$ & $0.99^{* b}$ \\
\hline Systolic BP (mmHg) & $167.13 \pm 31.47$ & $166.87 \pm 34.79$ & $0.15^{* c}$ \\
\hline Diastolic BP (mmHg) & $102.52 \pm 25.46$ & $103.24 \pm 23.47$ & $0.22^{* c}$ \\
\hline Hypertension, No. & 82 & 84 & $0.59^{* b}$ \\
\hline $\mathrm{Hb}(\mathrm{g} / \mathrm{dL})$ & $12.14 \pm 1.35$ & $12.36 \pm 1.12$ & $0.15^{* c}$ \\
\hline $\mathrm{BUN}(\mathrm{mg} / \mathrm{dL})$ & $43.37 \pm 15.31$ & $42.83 \pm 17.68$ & $0.16^{* c}$ \\
\hline eGFR $\left(\mathrm{ml} / \mathrm{min} / 1.73 \mathrm{~m}^{2}\right)$ & $13.15 \pm 3.43$ & $13.45 \pm 3.62$ & $0.48^{* c}$ \\
\hline Creatinine (mg/dL) & $10.71 \pm 1.48$ & $10.42 \pm 1.32$ & $0.27^{* c}$ \\
\hline $\begin{array}{l}\text { Dialysis duration } \\
\text { with respective } \\
\text { access (months) }\end{array}$ & $14.22 \pm 7.35$ & $14.68 \pm 7.22$ & $0.18^{* c}$ \\
\hline Type dialysis, No. & & & $0.37^{* b}$ \\
\hline Haemodialysis & 107 & 102 & \\
\hline Peritoneal dialysis & 5 & 8 & \\
\hline Ambulatory status & & & $0.47^{* a}$ \\
\hline Normal walking & 103 & 98 & \\
\hline $\begin{array}{l}\text { Walking with } \\
\text { assistive devices }\end{array}$ & 9 & 12 & \\
\hline $\begin{array}{l}\text { Completely } \\
\text { restricted walking }\end{array}$ & 0 & 0 & \\
\hline ASA level & & & $0.94^{* a}$ \\
\hline 1 & 31 & 34 & \\
\hline 2 & 47 & 40 & \\
\hline 3 & 34 & 36 & \\
\hline $\mathrm{BMD}$ & $-2.57 \pm 0.34$ & $-2.49 \pm 0.52$ & $0.47^{* c}$ \\
\hline $\mathrm{BMI}(\mathrm{kg} / \mathrm{m} 2)$ & $24.71 \pm 4.34$ & $25.12 \pm 4.61$ & $0.36^{* c}$ \\
\hline Personal history of VTEs & $16 / 112$ & $18 / 110$ & $0.67^{* b}$ \\
\hline Family history of VTES & $12 / 112$ & $14 / 110$ & $0.64^{* b}$ \\
\hline \multicolumn{4}{|l|}{ Diabetes mellitus } \\
\hline Duration, year & $19(4-26)$ & $18(5-24)$ & $0.14^{* c}$ \\
\hline Type 2, No. & 27 & 29 & $0.70^{* b}$ \\
\hline Insulin use, No. & 15 & 17 & $0.66^{* b}$ \\
\hline
\end{tabular}

$C L$ clopidogrel, BPS beraprost sodium, $B P$ blood pressure, $H b$ haemoglobin, $B U N$ blood urea nitrogen, eGFR estimated glomerular filtration rate, ASA

American Society of Anesthesiologists, BMD bone mineral density, BMI body mass index, VTEs vascular thromboembolic events

*No statistically significant values

${ }^{a}$ Analysed using the Mann-Whitney test

${ }^{\mathrm{b}}$ Analysed using the Chi-square test

'Analysed using an Independent-Samples t-test

[30]. Furthermore, in their study the divergent results cannot be explained. A growing but still very limited body of literature has shown that BPS tended to result in VTEs compared with CL $[19,25]$. This difference may be attributed to improved monitoring and management
Table 2 Between-group comparison of VTE incidence

\begin{tabular}{|c|c|c|c|}
\hline Variable & $\mathrm{CL}(n=112)$ & $\operatorname{BPS}(n=110)$ & $P$-value \\
\hline Total incidence of VTEs & $27 / 112$ & $13 / 110$ & $0.02^{* a}$ \\
\hline \multicolumn{4}{|l|}{ VTE incidence } \\
\hline During the first Mos & $16 / 112$ & $6 / 110$ & $0.03^{* a}$ \\
\hline $\begin{array}{l}\text { During the second } \\
\text { Mos }\end{array}$ & $3 / 112$ & $2 / 110$ & $0.64^{\mathrm{a}}$ \\
\hline $\begin{array}{l}\text { from the third Mos } \\
\text { to data cut-off }\end{array}$ & $8 / 112$ & $5 / 110$ & $0.41^{a}$ \\
\hline
\end{tabular}

CL clopidogrel, BPS beraprost sodium, VTEs vascular thromboembolic events, Mos month

*Statistically significant values

${ }^{a}$ Analysed using the Chi-square test

of VTEs. In addition, although VTEs were not detected in other cases with ESRD during the study, treatment in accordance with guidelines is advocated to manage VTE risk, and longer-term follow-up is necessary to ascertain any implications of the drug effect.

This study reflects the advantages of the relatively large sample size, which is inclined to provide statistical power to identify insignificant differences in the primary endpoint. The study excluded those cases with high risk for VTEs. Although such cases would be inclined to suffer a VTE, they also have a high rate of some other complications, which could result in high rates of withdrawal. Although our study has basically achieved the desired results, as a retrospective study that BPS is a more optimistic for ESRD patients in preventing VTEs compared with $\mathrm{CL}$, there are inevitably some limitations. Firstly, between-study comparisons might tend to be confounded by differences in population included. Secondly, surgeon- and patient- related confounders may be inevitable. Nevertheless, improvement in the success rate of VTEs remained noteworthy, which had been proved by the final logistic regression assessment after adjusting some potentially and relatively imbalanced variates.

Table 3 VTE risk ratio between groups

\begin{tabular}{lllc}
\hline Variable & $\mathrm{CL}(n=112)$ & BPS $(n=110)$ & $P$ - value \\
\hline Total VTE HR (95\%Cl) & 6.98 & 3.42 & $0.001^{*}$ \\
& $(3.17-18.61)$ & $(1.46-8.53)$ & \\
VTE HR (95\%Cl) & & & \\
during 1st Mos & 7.15 & 3.29 & $0.135^{*}$ \\
& $(2.49-15.11)$ & $(1.21-6.67)$ & \\
during 2nd Mos & 26.58 & 24.37 & $0.181^{*}$ \\
& $(8.53-89.17)$ & $(7.64-101.72)$ & \\
from 3rd Mos to & 19.36 & 14.15 & $0.214^{*}$ \\
data cut-off & $(6.62-86.19)$ & $(5.13-86.24)$ & \\
\hline
\end{tabular}

CL clopidogrel, BPS beraprost sodium, VTE vascular thromboembolic event, $H R$ hazard ratio, $\mathrm{Cl}$ confidence interval, Mos month

*Statistically significant values 


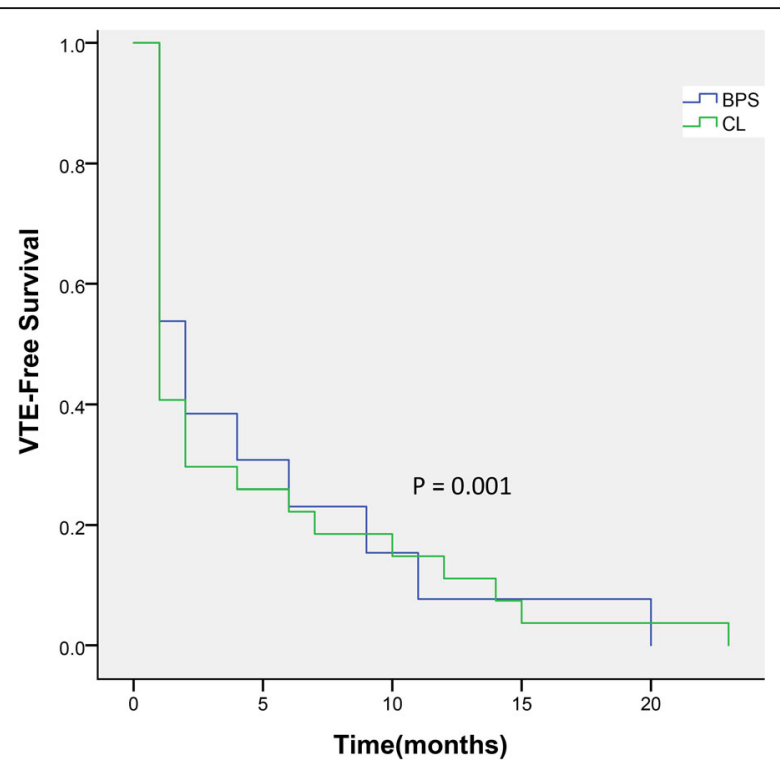

Fig. 2 Kaplan-Meier estimates of vascular thromboembolic events (VTEs) of arteriovenous fistula (AVF) between groups. At the final follow-up, the incidence of VTEs was higher in the $C L$ group than in the BPS group ( $P=0.001$ by Kaplan-Meier test). VTE-Free survival (time to first on-study VTE) comparing clopidogrel (CL) versus beraprost sodium (BPS)

\section{Conclusions}

The study demonstrates, as anticipated, the superiority of BPS over CL in ESRD patients using time to first on-study VTE as the primary study endpoint regardless of the follow-up period. Compared with CL, BPS shows a decreased risk for VTEs, the long-term significance of which remains to be clarified. However, the superior efficacy of BPS in the current study offers preliminary evidence of a benefit-risk that corroborates its application in ESRD cases receiving an AVF surgery.

\section{Abbreviations}

ASA: American Society of Anesthesiologists; AVF: Arteriovenous fistula; BMD: Bone mineral density; BMI: Body mass index; BP: Blood pressure; BPS: Beraprost sodium; BUN: Blood urea nitrogen; Cl: Confidence interval; CL: Clopidogrel; eGFR: Estimated glomerular filtration rate; EJC: Endpoint Judgment Committee; ESRD: End-stage renal disease; Hb: Haemoglobin; HR: Hazard ratio; IQR: Interquartile range; Mos: Month; SD: Standard deviation; VTEs: Vascular thromboembolic events

\section{Acknowledgements}

The authors would like to thank Xingfei Zhu for help with retrieval of patients' notes and radiographs.

\section{Funding}

Funding for this research was received from the Shanghai Municipal Health and Family Planning Commission Fund Project (Grant No. 201640057), and the National Natural Science Foundation of China (Grant No. 81770876; $81270011 ; 81472125)$. The funding body did not play a role in the design of the study and collection, analysis, and interpretation of data and in writing the manuscript.

\section{Availability of data and materials}

The datasets used and/or analysed during the current study available from the corresponding author on reasonable request.

\section{Authors' contributions}

$Y Z, L D, B T, Q L$ and BX performed the data collection and analysis and participated in manuscript writing. XD performed the database setup and statistical analysis. FZ, MZ and ZW performed the operations. YZ and JL participated in the study design and coordination and helped to draft the manuscript. All of the authors have read and approved the final manuscript.

\section{Ethics approval and consent to participate}

The study was approved by the institutional ethics review boards (Jinshan Hospital, Fudan University; the First Affiliated Hospital, Sun Yat-sen University; the First Affiliated Hospital of Chongqing Medical University), and an exemption for informed consent was obtained from these Investigational Ethical Review Boards.

\section{Consent for publication}

Not applicable

\section{Competing interests}

The authors declare that they have no competing interests.

\section{Publisher's Note}

Springer Nature remains neutral with regard to jurisdictional claims in published maps and institutional affiliations.

\section{Author details}

'Department of Nephrology, The First Affiliated Hospital of Chongqing Medical University, Youyi Road No.1, Yuzhong District, Chongqing 400016, China. ${ }^{2}$ Department of Anesthesiology, The Central Hospital of Wuhan, Tongji Medical College, Huazhong University of Science and Technology, Gusao Road No. 16, Jianghan District, Wuhan 430014, Hubei, China. ${ }^{3}$ Department of Ultrasonography, The First Affiliated Hospital of Chongqing Medical University, Youyi Road No.1, Yuzhong District, Chongqing 400016, China. ${ }^{4}$ Department of Thoracic surgery, The First Affiliated Hospital of Sun Yat-sen University, Huangpu East Road No. 183, Huangpu District, Guangzhou 510700, China. ${ }^{5}$ Radiology Department, The First Affiliated Hospital of Sun Yat-sen University, Huangpu East Road No. 183, Huangpu District, Guangzhou 510700, China. ${ }^{6}$ Department of Orthopaedics, Jinshan Hospital, Fudan University, Longhang Road No. 1508, Jinshan District, Shanghai 201508, China. 'Department of Gynaecology and obstetrics, The First Affiliated Hospital of Sun Yat-sen University, Huangpu East Road No. 183, Huangpu District, Guangzhou 510700, China.

Received: 8 January 2018 Accepted: 30 November 2018 Published online: 27 December 2018

\section{References}

1. Salako AA, Badmus TA, lgbokwe MC, David RA, Laoye A, Akinbola IA, et al. Experience with arteriovenous fistula creation for maintenance hemodialysis in a tertiary Hospital in South-Western Nigeria. Saudi J Kidney Dis Transpl. 2018;29(4):924-9. https://doi.org/10.4103/1319-2442.239628.

2. Pataniappan S, Subbiah V, Gopalan VR, Kumar PV, Vinothan RJS. Observational study of the efficacy of supraclavicular brachial plexus block for arteriovenous fistula creation. Indian J Anaesth. 2018;62(8):616-20. https://doi.org/10.4103/ija.IJA_293_18.

3. McGrogan DG, Stringer S, Cockwell P, Jesky M, Ferro C, Maxwell AP, et al. Arterial stiffness alone does not explain arteriovenous fistula outcomes. J Vasc Access. 2018;19(1):63-8. https://doi.org/10.5301/jva.5000791.

4. Kocaaslan C, Kehlibar T, Yilmaz M, Mehmetoglu ME, Gunay R, Aldag M, et al. Outcomes of arteriovenous fistula for hemodialysis in octogenarian population. Vascular. 2018;26(5):509-14. https://doi.org/10.1177/1708538118762067.

5. Mannava K, Money SR. Current management of peripheral arterial occlusive disease - a review of pharmacologic agents and other interventions. Am J Cardiovasc Drugs. 2007;7(1):59-66. https://doi.org/10.2165/00129784-200707010-00005.

6. Ihara K, Ohashi A, Inoshita S. Risk of heparin-induced immediate-type hypersensitivity during arteriovenous fistula placement. Intern Med. 2018; 57(16):2365-9. https://doi.org/10.2169/internalmedicine.9705-17.

7. Douglass A, Allen C, Presson A, Sarfati MR, Griffin CL, Smith BK, et al. Patientreported outcomes in patients with end-stage renal disease: is quality of life affected when catheters are used for hemodialysis versus arteriovenous fistulas? J Vasc Surg. 2018;67(6):E200-E. https://doi.org/10.1016/j.jvs.2018.03.291. 
8. Diandra JC, Lo ZJ, Ang WW, Feng JF, Narayanan S, Tan GWL, et al. A review of arteriovenous fistulae creation in octogenarians. Ann Vasc Surg. 2018;46: 331-6. https://doi.org/10.1016/j.avsg.2017.07.021.

9. Tham WP, Burgmans MC, Tan BS, Tay KH, Irani FG, Gogna A, et al. Percutaneous endovascular treatment to salvage non-maturing arteriovenous fistulas in a multiethnic Asian population. Ann Acad Med Singap. 2017;46(2):64-71.

10. Kim M, Kim JU, Kim SM, Kim H. Effectiveness of beraprost sodium in maintaining vascular access patency in patients on hemodialysis. Int Urol Nephrol. 2017;49(7):1287-95. https://doi.org/10.1007/s11255-017-1586-y.

11. Shehab N, Sperling LS, Kegler SR, Budnitz DS. National estimates of emergency department visits for hemorrhage-related adverse events from Clopidogrel plus aspirin and from warfarin. Arch Intern Med. 2010;170(21): 1926-33. https://doi.org/10.1001/archinternmed.2010.407.

12. Kelly RP, Close SL, Farid NA, Winters KJ, Shen L, Natanegara F, et al. Pharmacokinetics and pharmacodynamics following maintenance doses of prasugrel and clopidogrel in Chinese carriers of CYP2C19 variants. Br J Clin Pharmacol. 2012;73(1):93-105. https://doi.org/10.1111/j.1365-2125.2011.04049.x

13. li M, Hoshiga M, Fukui R, Negoro N, Nakakoji T, Nishiguchi F, et al. Beraprost sodium regulates cell cycle in vascular smooth muscle cells through CAMP signaling by preventing down-regulation of p27(Kip1). Cardiovasc Res. 2001; 52(3):500-8. https://doi.org/10.1016/s0008-6363(01)00411-4.

14. Cheng $\mathrm{Q}$, Zhao YJ. The reasons for the failure of the primary arteriovenous fistula surgery in patients with end-stage renal disease (vol 16, pg S74, 2015). J Vasc Access. 2016;17(1):101. https://doi.org/10.5301/jva.2016.15410.

15. Patel ST, Hughes J, Mills JL. Failure of arteriovenous fistula maturation: an unintended consequence of exceeding Dialysis outcome quality initiative guidelines for hemodialysis access. J Vasc Surg. 2003;38(3):439-45. https:// doi.org/10.1016/s0741-5214(03)00732-8.

16. Romaozinho C, Escada L, Macario F. Arteriovenous fistula: Survival impact on patients with end-stage renal disease initiating hemodialysis. Am J Kidney Dis. 2006;47(4):A52-A

17. Raje N, Terpos E, Willenbacher W, Shimizu K, Garcia-Sanz R, Durie B, et al. Denosumab versus zoledronic acid in bone disease treatment of newly diagnosed multiple myeloma: an international, double-blind, doubledummy, randomised, controlled, phase 3 study. Lancet Oncol. 2018;19(3): 370-81. https://doi.org/10.1016/s1470-2045(18)30072-x.

18. Fischer MJ, Ho PM, McDermott K, Lowy E, Parikh CR. Chronic kidney disease is associated with adverse outcomes among elderly patients taking clopidogrel after hospitalization for acute coronary syndrome. BMC Nephrol. 2013;14. https://doi.org/10.1186/1471-2369-14-107.

19. Tanner NC, Da Silva A. Medical adjuvant treatment to increase patency of arteriovenous fistulae and grafts. Cochrane Database Syst Rev. 2015;(7). https://doi.org/10.1002/14651858.CD002786.pub3.

20. Fifi JT, Brockington C, Narang J, Leesch W, Ewing SL, Bennet $\mathrm{H}$, et al. Clopidogrel resistance is associated with thromboembolic complications in patients undergoing neurovascular stenting. AJNR Am J Neuroradiol. 2013; 34(4):716-20. https://doi.org/10.3174/ajnr.A3405.

21. Dember LM, Beck GJ, Allon M, Delmez JA, Dixon BS, Greenberg A, et al. Effect of clopidogrel on early failure of arteriovenous fistulas for hemodialysis - a randomized controlled trial. JAMA. 2008;299(18):2164-71. https://doi.org/10.1001/jama.299.18.2164.

22. Gersch MS. Clopidogrel decreases arteriovenous fistula thrombosis but does not improve fistula maturation. Nat Clin Pract Nephrol. 2008;4(9):476-7. https://doi.org/10.1038/ncpneph0908.

23. Chemla ES, Morsy M. A European perspective on the Dialysis access consortium (DAC) study regarding the effects of Clopidogrel on early failure of arteriovenous fistulas for hemodialysis. J Vasc Access. 2008;9(4):229-30.

24. Lee T, Ullah A, Allon M, Succop P, El-Khatib M, Munda R, et al. Decreased cumulative access survival in arteriovenous fistulas requiring interventions to promote maturation. Clin J Am Soc Nephrol. 2011;6(3):575-81. https:// doi.org/10.2215/cjn.06630810

25. Arenas MD, Perez R, Rodriguez JA. Embolism as a cause of early thrombosis of arteriovenous fistula for hemodialysis. Nefrologia. 2017;37(5):556-7. https://doi.org/10.1016/j.nefro.2016.12.005.

26. Tong XY, Hou XY, Wason C, Kopel T, Cohen RA, Dember LM. Smooth muscle nitric oxide responsiveness and clinical maturation of hemodialysis arteriovenous fistulae. Am J Pathol. 2017;187(9):2095-101. https://doi.org/10. 1016/j.ajpath.2017.05.006

27. Coleman Cl, Tuttle LA, Teevan C, Baker WL, White CM, Reinhart KM. Antiplatelet agents for the prevention of arteriovenous fistula and graft thrombosis: a meta analysis. Int J Clin Pract. 2010;64(9):1239-44. https://doi. org/10.1111/j.1742-1241.2009.02329.x.

28. Moriya H, Ishioka K, Honda K, Oka M, Maesato K, Ikee R, et al. Beraprost sodium, an orally active prostaglandin I-2 analog, improves renal Anemia in hemodialysis patients with peripheral arterial disease. Ther Apher Dial. 2010; 14(5):472-6. https://doi.org/10.1111/j.1744-9987.2010.00814.x.

29. Shimamura M, Miyakawa J, Doi M, Okada K, Kurumatani H, Mori Y, et al. The pharmacokinetics of Beraprost sodium following single Oral administration to subjects with impaired kidney function. J Clin Pharmacol. 2017;57(4):52435. https://doi.org/10.1002/jcph.835.

30. Hochholzer W, Trenk D, Fromm MF, Valina CM, Stratz C, Bestehorn HP, et al. Impact of cytochrome P450 2C19 loss-of-function polymorphism and of major demographic characteristics on residual platelet function after loading and maintenance treatment with Clopidogrel in patients undergoing elective coronary stent placement. J Am Coll Cardiol. 2010; 55(22):2427-34. https://doi.org/10.1016/j.jacc.2010.02.031.

31. Floyd JS, Kaspera R, Marciante KD, Weiss NS, Heckbert SR, Lumley T, et al. A screening study of drug-drug interactions in Cerivastatin users: an adverse effect of Clopidogrel. Clin Pharmacol Ther. 2012;91(5):896-904. https://doi. org/10.1038/clpt.2011.295.

32. Bavare CS, Street TK, Peden EK, Davies MG, Naoum JJ. Stent grafts can convert unusable upper arm arteriovenous fistulas into a functioning hemodialysis access: a retrospective case series. Front Surg. 2017;4. https:// doi.org/10.3389/fsurg.2017.00013.

33. Yuo TH, Chaer RA, Dillavou ED, Leers SA, Makaroun MS. Patients started on hemodialysis with tunneled dialysis catheter have similar survival after arteriovenous fistula and arteriovenous graft creation. J Vasc Surg. 2015; 62(6):1590. https://doi.org/10.1016/j.jvs.2015.07.076.
Ready to submit your research? Choose BMC and benefit from:

- fast, convenient online submission

- thorough peer review by experienced researchers in your field

- rapid publication on acceptance

- support for research data, including large and complex data types

- gold Open Access which fosters wider collaboration and increased citations

- maximum visibility for your research: over $100 \mathrm{M}$ website views per year

At $\mathrm{BMC}$, research is always in progress.

Learn more biomedcentral.com/submissions 